\title{
Solar pyrolysis of cotton stalk in molten salt for bio-fuel production
}

\author{
Yingpu Xie a , Kuo Zeng a, b, c, *, Gilles Flamant ${ }^{\text {c }}$, Haiping Yang ${ }^{\text {a }}$, Nian Liu ${ }^{\text {a }}$, Xiao He ${ }^{\text {a }}$, \\ Xinyi Yang ${ }^{a}$, Ange Nzihou ${ }^{\mathrm{d}}$, Hanping Chen ${ }^{\mathrm{a}}$ \\ a State Key Laboratory of Coal Combustion, Huazhong University of Science and Technology, 1037 Luoyu Road, Wuhan, Hubei, 430074, PR China \\ b Shenzhen Huazhong University of Science and Technology Research Institute, Shenzhen, 523000, China

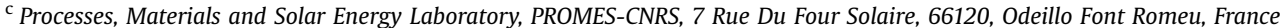 \\ d Université; de Toulouse, Mines Albi, UMR CNRS 5302, Centre RAPSODEE, Campus Jarlard, F-81013, Albi cedex 09, France
}

\section{A B S T R A C T}

Solar pyrolysis of cotton stalk was carried out in a molten salt reactor heated by $4 \mathrm{~kW}$ solar simulator. The effects of pyrolysis temperature and mass ratio of molten salt to biomass on pyrolysis products properties were investigated. The use of molten salt as pyrolysis media increased gas yield. At $850^{\circ} \mathrm{C}$, the gas yield (mainly of $\mathrm{CO}$ and $\mathrm{H}_{2}$ ) continued to rise from $41.35 \mathrm{wt} \%$ to $82.57 \mathrm{wt} \%$ when mass ratio of molten salt to cotton stalk increased from 0 to 10 . Pyrolysis in molten salt significantly decreased bio-oil acids and phenols, while increased aromatics among pyrolysis temperature range of $450-850^{\circ} \mathrm{C}$. There was positive correlation between the increased content of aromatics and mass ratio of molten salt to cotton stalk (from 0.5 to 10). The bio-char carbon content showed a general decreasing trend while oxygen, BET surface area and pore volume increased with using molten salt as pyrolysis media. Bio-char obtained from CS1MS5 pyrolysis at $850^{\circ} \mathrm{C}$ had the highest BET surface area of $972.57 \mathrm{~m}^{2} / \mathrm{g}$ and the biggest total pore volume of $0.6203 \mathrm{~cm}^{3} / \mathrm{g}$. High quality pyrolysis products with more uniform chemistry suggest catalytic reactions occur inside the solar reactor due to the intermediates degradation with molten salt.

Keywords:

Solar pyrolysis

Molten salt

Cotton stalk

Bio-gas

Bio-char

\section{Introduction}

Due to the negative environmental impacts of fossil fuels and the increasing global energy demands, biofuels are receiving increasing attention as the best short-term substitute for petroleum fuels. Pyrolysis is a promising thermochemical process for converting biomass into biofuels (bio-gas, bio-oil and bio-char) [1]. However, the thermal energy driving the pyrolysis process is typically drawn from combustion of the feedstock or other fossil energy sources. To produce a truly carbon-neutral fuel and maximize the yield of biofuel per unit biomass consumed, the energy driving the pyrolysis reactions must come from a renewable energy source. Concentrated solar energy fits the requirements of a heat source for an externally heated pyrolysis process. Solar radiation is concentrated using mirrors to provide temperatures high enough to drive biomass pyrolysis reactions that are able to store this solar thermal energy in a chemical form as biofuels [2-4].

Supplying process heat with concentrated solar energy has

\footnotetext{
* Corresponding author. ; 1037 Luoyu Road, Wuhan, Hubei, 430074, PR China. E-mail address: zengkuo666@hust.edu.cn (K. Zeng).
}

numerous advantages over conventional pyrolysis [5]. There is no need for partial combustion which allowing all of the feedstock to be upgraded into bio-fuel; the product gas contains low $\mathrm{CO}_{2}$ and $\mathrm{N}_{2}$, and no other combustion by-products; the energetic value of the product is greater than that of the feedstock. Besides, pyrolysis driven by direct concentrated solar irradiation has the benefits of high temperatures and rapid heating rates [6]. The biomass can be rapidly heated to around $500^{\circ} \mathrm{C}$ and thus maximizes exposure to the higher temperatures that favor vapors formation. Hence, high yields of bio-oil will be obtained at normal pyrolysis temperatures of about $500{ }^{\circ} \mathrm{C}$ because vapors passing from the high temperature region (the focus of concentrated solar radiation) to the low temperature zone (the surrounding gas) are quickly condensed, thus minimizing the secondary decomposition of primary tar into gas [7]. Fuel calorific value of carbonaceous feedstock can be upgraded by direct solar pyrolysis process, which enables the storage of solar energy in chemical form as bio-oil, bio-char and bio-gas whose proportion mainly depending on the temperature $[8,9]$.

The previous work on pyrolysis driven by direct irradiation of concentrated solar energy has demonstrated many benefits, however issues related to transient sensitivity, poor heat transfer and 
tar production have been persistent motivating the search for an improved approach to solar pyrolysis. Concentrated solar energy can be effectively stored in molten salt, then providing high temperature heat for biomass pyrolysis [10]. The use of molten salts allowed the continuous operation of solar pyrolysis system. Besides, the biomass particles can be dispersed in molten salt, which is beneficial to enhancing the bio-fuels production rate and yield. This can be attributed to two main reasons [11]: fast heat transfer rate and catalytic effect of alkali metal-based catalyst. The fast heat transfer was attributed to a high convective heat transfer with high heat capacity [12]. The alkali metal cations play an important role in the catalytic phenomenon of biomass pyrolysis with three main steps: (1) biomass devolatilization; (2) tar and char formation and (3) tar dissociation by molten salt [13].

Several researchers have performed laboratory bench scale experiments using molten salt for biomass pyrolysis. The temperature, amount and composition of molten salt have been shown to influence the pyrolysis reactions. The heating rates of sapwood pyrolysis at $600-900^{\circ} \mathrm{C}$ in molten salt were $4-10$ times higher than those without molten salt, the heating rate can be up to $4100-16700^{\circ} \mathrm{C} / \mathrm{min}$ in a mixture of sodium chloride $(\mathrm{NaCl})$ and potassium chloride $(\mathrm{KCl})$ at $900^{\circ} \mathrm{C}$ [14]. Maximum heating rates for cylindrical beech wood pellet (30 mm length and $3.5 \mathrm{~mm}$ diameter) pyrolysis in LiNaKF salt were $46-56^{\circ} \mathrm{C} / \mathrm{s}$ [15]. The total energy input required for wood pyrolysis at $900{ }^{\circ} \mathrm{C}$ equal about $20 \%$ of its heating value [16].

Besides, molten salt changed the proportion of three-state products. When wood pyrolysis in molten carbonates, the yield of liquid products decreased while the yields of gas and char increased [17]. Higher gas yield and less complex bio-oil composition were obtained in a bath of nitrate molten salts (60 wt\% $\mathrm{NaNO}_{3}$ and $40 \mathrm{wt} \% \mathrm{KNO}_{3}$ ) at $500{ }^{\circ} \mathrm{C}$ [18]. The yields of bio-oil obtained from cellulose/rice stalk pyrolysis in mixtures of metal chlorides and nitrates molten salts at temperatures ranges of $400-600{ }^{\circ} \mathrm{C}$ increased and then decreased with increasing temperature, and the optimal temperature was $530^{\circ} \mathrm{C}$ [19]. Lignin was pyrolyzed in mixtures of molten salt $\left(\mathrm{ZnCl}_{2}\right.$ and $\left.\mathrm{KCl}\right)$ with molar ratios of $3 / 7$ and $7 / 6$ at temperatures from 500 to $800^{\circ} \mathrm{C}$ [20]. It was found that a molar ratio of $7 / 6$ at $600^{\circ} \mathrm{C}$ had a high selectivity to cresols with a maximum yield of $4.6 \mathrm{wt} \%$. The effect of salt amount was also investigated with different salt-to-lignin ratios (1, 2 and 3 ) [21]. In addition, the lowest yields of gas products and the highest yield of phenolic compounds except for phenol were obtained at salt-to-lignin ratio of 1 . The presence of molten salt in cellulose pyrolysis could increase its conversion to syngas by $30 \%$ at $850{ }^{\circ} \mathrm{C}$ and the maximum conversion of $98 \mathrm{wt} \%$ was achieved at $915^{\circ} \mathrm{C}$ [22]. The use of molten salt increased the total hydrocarbon compounds with decreasing oxygenated compounds during coal pyrolysis [23].

Most of these studies were focused on the distribution and composition of products obtained from pyrolysis in molten salt. However, little information is available on the formation mechanism and mutual transformation process of products during solar pyrolysis of biomass in molten salt, despite this information is very important for realizing the high-valued conversion of biomass. Therefore, it is necessary to deeply investigate all products (bio-oil, bio-char and bio-gas) for revealing pathways of intermediates degradation with molten salt. In this study, solar pyrolysis of cotton stalk in molten salt $\left(\mathrm{Li}_{2} \mathrm{CO}_{3}-\mathrm{Na}_{2} \mathrm{CO}_{3}-\mathrm{K}_{2} \mathrm{CO}_{3}\right)$ was conducted in a $4 \mathrm{~kW}$ solar simulator reactor. The effects of temperature $(450,550$, 650,750 and $850^{\circ} \mathrm{C}$ ) and molten salt amount (the mass ratio of molten salt to biomass was $0.5,1,5$ and 10 ) on the molten salt pyrolysis of biomass were investigated by characterizing the total products.

\section{Experimental}

\subsection{Experimental sample}

\subsubsection{Cotton stalk}

Cotton stalk (CS) was crushed into small particles with size of $0.1-0.4 \mathrm{~mm}$, and then dried at $105^{\circ} \mathrm{C}$ for $24 \mathrm{~h}$. The proximate analysis of the air-dried cotton stalk feedstock was $77.49 \mathrm{wt} \%$ volatile, $4.60 \mathrm{wt} \%$ ash, $16.04 \mathrm{wt} \%$ fixed carbon, and $1.86 \mathrm{wt} \%$ moisture. The elemental composition of the dried feedstock was $46.56 \mathrm{wt} \%$ carbon, $6.04 \mathrm{wt} \%$ hydrogen, $41.82 \mathrm{wt} \%$ oxygen, and $0.79 \mathrm{wt} \%$ nitrogen.

\subsubsection{Molten salt}

Lithium, sodium and potassium carbonates (analytical purity $>99 \%$, Sinopharm Chemical Reagent Co., Ltd, Shanghai, China) were well-mixed with mass ratio of $1: 1: 1$. Then, the ternary eutectic blend salts were put in a corundum crucible and heated to $600{ }^{\circ} \mathrm{C}$ for $2 \mathrm{~h}$ in muffle furnace. The salts were crushed into fine particles by a grinder once they were cooled down to atmospheric temperature. The fine particle salts were defined as molten salts (MS), and the melting point of MS was approximately $400^{\circ} \mathrm{C}$ [24].

\subsubsection{Pyrolysis feedstock}

For each pyrolysis experiment, about $1 \mathrm{~g}$ of cotton stalk was weighted then well mixed with MS. The mass ratio of MS to cotton stalk for mixture were $0,0.5,1,5,10$ denoted as CS, CS1MS0.5, CS1MS1, CS1MS5 and CS1MS10, respectively.

\subsection{Experimental procedure}

\subsubsection{Experimental setup}

Solar pyrolysis experiments were performed in molten salt reactor heated by a $4 \mathrm{~kW}$ solar simulator instead of the real sun as shown in Fig. 1. Solar simulators can overcome the shortcomings of real sunlight such as the periodicity and randomness of solar irradiance [25]. What's more, they can present significant advantages in terms of size, cost and operational flexibility [26]. They are very important and valuable for fast and cost-effective indoor laboratory in certain research fields, such as the pyrolysis [27] and gasification [28] of carbonaceous feedstock.

The solar simulator consists of three $5 \mathrm{~kW}$ xenon arc lamps and three accompanying parabolic concentrators. The lamps and concentrator are adjusted to the right position making sure the focus in the same point. The position of solar simulator focus can be changed by adjustable screw devices. The solar simulator can produce concentrated radiation similar to the solar spectral pattern (mostly in the visible and IR spectra) [29], with irradiative flux densities ranging from 0.2 to $1.5 \mathrm{MW} / \mathrm{m}^{2}$ within $800 \mathrm{~mm}$ diameter circle. A shutter with moving parallel carbon composite blades modulates the concentrated flux impinging molten salt reactor and finally the pyrolysis sample temperature. The molten salt reactor is a $30 \mathrm{~mm}$ diameter by $40 \mathrm{~mm}$ long cylindrical graphite crucible within a $150 \mathrm{~mm}$ transparent Pyrex balloon enclosure, which is positioned vertically at the solar simulator focus. Temperature sensor (K-type thermocouple) is sited at the rear of the reactor in contact with the reactor inner wall to measure the sample temperature. The required heating rate and temperature are set on a PID controller, which controls the shutter opening based on the measured sample temperature. The balloon is swept with nitrogen flow controlled by a mass flowmeter for keeping wall clean.

\subsubsection{Experimental procedure}

The pyrolysis sample was weighed and placed into the graphite crucible (molten salt reactor). The graphite crucible was put inside 


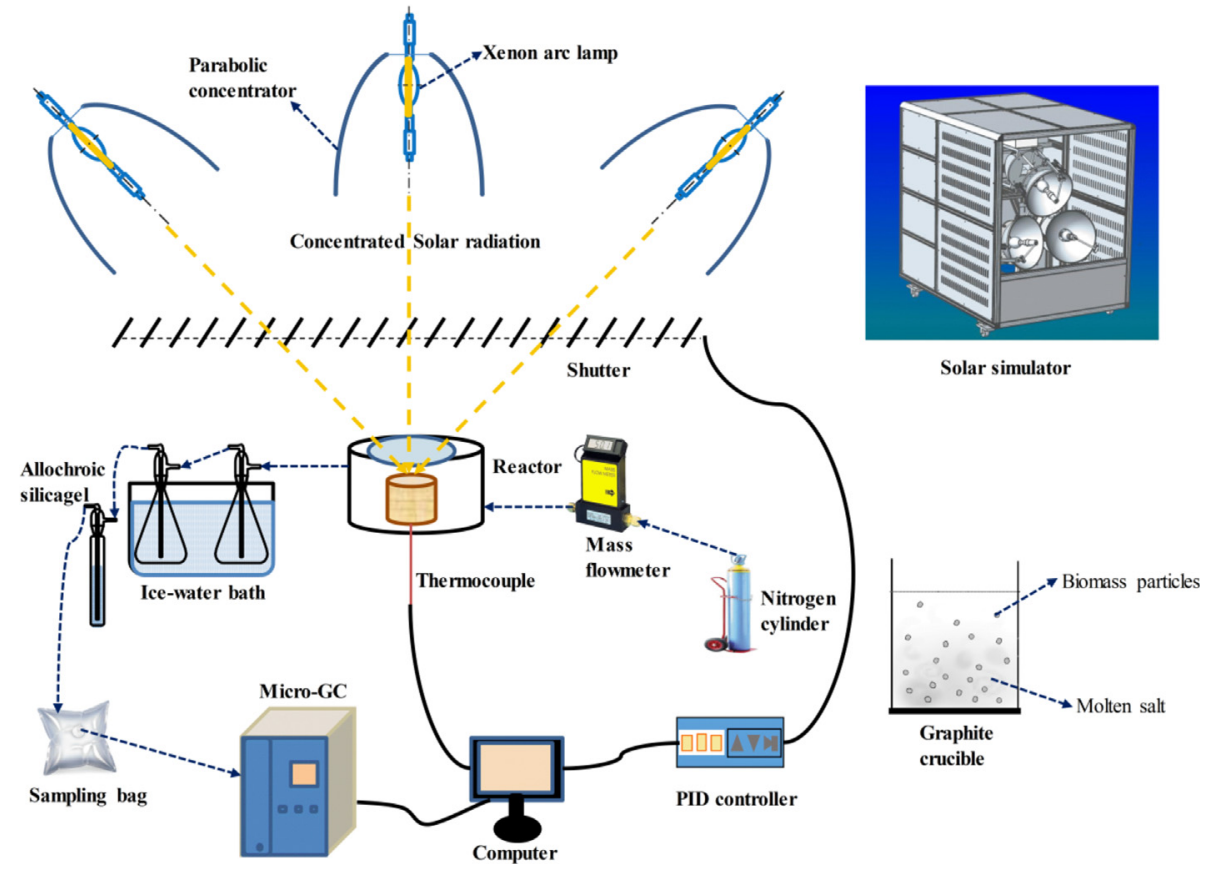

Fig. 1. Schematic of the solar pyrolysis in molten salt experimental setup.

the transparent Pyrex balloon and set at the solar simulator focus. The balloon was purged in 3 min by nitrogen gas with a flow rate of $2000 \mathrm{ml} / \mathrm{min}$ for inert atmosphere. Then the pyrolysis unit swept by $500 \mathrm{ml} / \mathrm{min}$ nitrogen was heated to target temperatures $(450$, $550,650,750$ and $850^{\circ} \mathrm{C}$ ) at heating rate of $10^{\circ} \mathrm{C} / \mathrm{s}$ with PID controller on. The pyrolysis temperature was remained stable for 30 min until the reaction was completed. The gas mixture produced from pyrolysis was cooled by the ice-water mixture condensing unit for the condensable volatiles collection, whereas the noncondensing gas was collected with gas bag. After each run, the solid residues were retained in graphite crucible after turning off the solar simulator. The carrier gas flow was still on for 5 min until solid residues cooled to the ambient temperature. Each experiment was run at least three times to ensure the repeatability. The RSD for the experiment was less than $5 \%$. The error bars indicate $95 \%$ confidence intervals.

\subsubsection{Product recovery and characterization}

According to molten salt mass ratio in pyrolysis feedstock, the solid residues was washed with sufficient amount of hydrochloric acid solution $(1 \mathrm{~mol} / \mathrm{L})$ for removing molten salt. The mixture was stirred in the magnetic agitator for $3 \mathrm{~h}$ at room temperature. After stirring, suction filtration device was utilized to filter and wash suspension mixture until the filtrate was neutral. The solid left after filtration was dried at $105^{\circ} \mathrm{C}$ in oven to constant weight, and then was weighed and recorded as the "bio-char" yield. The "gas" yield was calculated by combining the volumes of all the gases collected in the gas bag. The "bio-oil" yield was calculated by the mass difference of the conical condenser after the reaction.

The bio-char was weighed and characterized as our previous study [30]. Ultimate analysis was carried out in a CHNS/O elementary analyzer (Vario Micro Cube, Germany). The specific surface area and pore size distribution were analyzed with Surface Area and Porosity analyzer (TriStar II, Micromeritics Instrument Corp., Norcross, USA). Prior to each analysis, the sample was degassed at the temperature of $150^{\circ} \mathrm{C}$ under a vacuum for $20 \mathrm{~h}$. Nitrogen adsorption isotherm was obtained at the temperature of $-196{ }^{\circ} \mathrm{C}$ in the relative pressures $\left(\mathrm{P} / \mathrm{P}_{0}\right)$ range between 0.05 and 0.99 . The BET surface area, micropore volume and total pore volume were calculated with the Brunauer-Emmett-Teller (BET) equation, t-plot method and single point adsorption total pore volume analysis, respectively [31].

The gas compositions were analyzed using a dual-channel gas chromatography (Panna A91, Panna Instruments Co., Ltd, Changzhou, China). $\mathrm{H}_{2}, \mathrm{~N}_{2}, \mathrm{O}_{2}, \mathrm{CO}_{2}, \mathrm{CH}_{4}$ and $\mathrm{CO}$ were separated by Porapak Q column and $5 \mathrm{~A}$ zeolite molecular sieve column with He as carrier gas and analyzed by a thermal conductivity detector (TCD). Olefins and alkanes $\left(\mathrm{C}_{2+}\right)$ were separated using a $\mathrm{Al}_{2} \mathrm{O}_{3} / \mathrm{KCl}$ capillary column with $\mathrm{N}_{2}$ as carrier gas and analyzed by a flame ionization detector (FID). Content of $\mathrm{N}_{2}$ in produced gas was calculated as the reference to obtain the yield of each gas. Heating program of columns was set as below, columns was maintained at $80^{\circ} \mathrm{C}$ for $4 \mathrm{~min}$ and heated to $150^{\circ} \mathrm{C}$ at a heating rate of $10^{\circ} \mathrm{C} / \mathrm{min}$, then maintained at $150^{\circ} \mathrm{C}$ for $6 \mathrm{~min}$.

The main compositions of bio-oil were determined using gas chromatography-mass spectrometry (GC-MS; Agilent 7890 A series GC coupled with an HP5975 MS detector) with He. The detail of GCMS and test method has already been described in our previous study [32]. All the compounds were identified based on NIST mass spectral data library with response factors for GC quantification determined by internal standard method [4].

\section{Results and discussion}

\subsection{Final product distribution}

Fig. 2 compares the products distribution from solar pyrolysis of cotton stalk without and with molten salt. For CS pyrolysis (without molten salt), the gas yield noticeably increased from $24.09 \mathrm{wt} \%$ to $41.35 \mathrm{wt} \%$ when pyrolysis temperature increased from 450 to $850^{\circ} \mathrm{C}$ shown in Fig. $2 \mathrm{a}$, while the liquid yield significantly decreased from $42.08 \mathrm{wt} \%$ to $33.65 \mathrm{wt} \%$ indicated in Fig. $2 \mathrm{~b}$, char yield decreased from 34.64 wt\% to $25.11 \mathrm{wt} \%$ depicted in Fig. 2c. This result suggests that the increase in the gas yield is primarily 

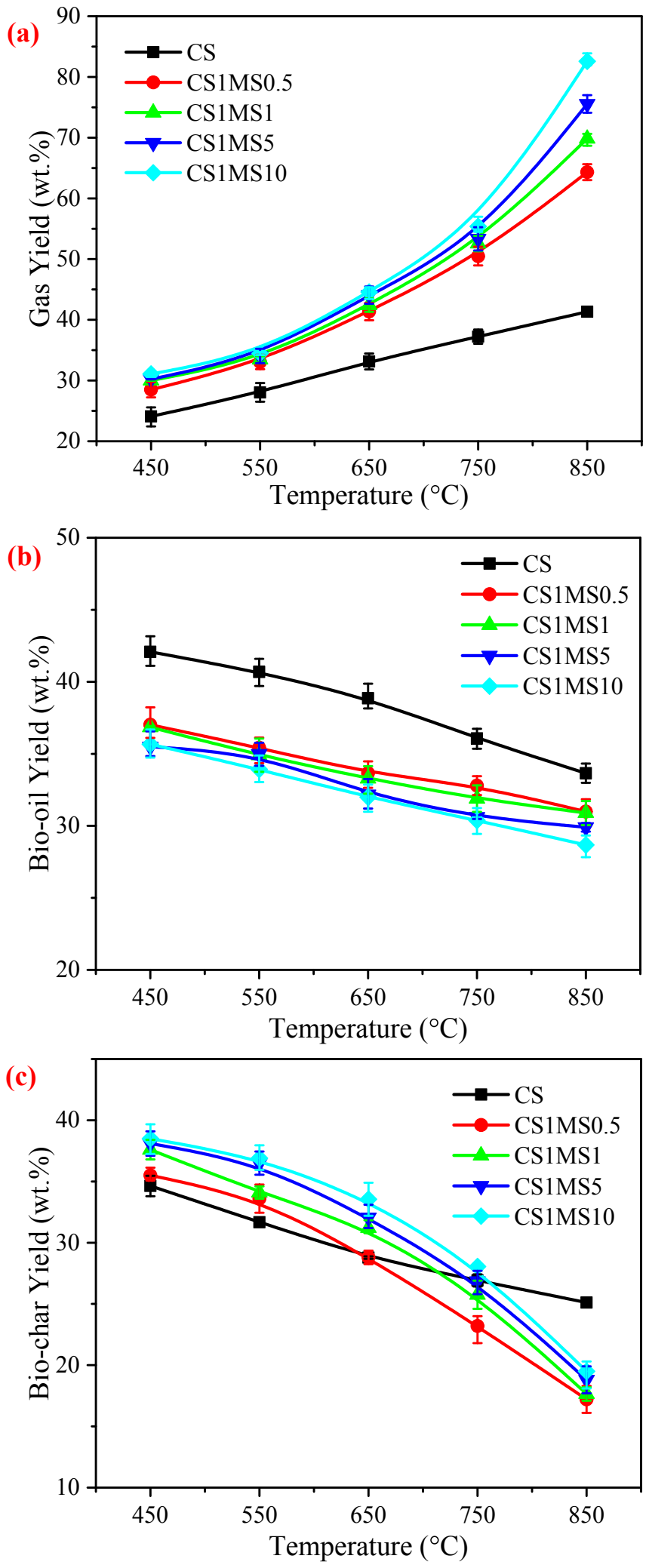

Fig. 2. Effects of temperature and molten salt amount on the product distribution of solar pyrolysis: (a) Bio-gas yield, (b) Bio-oil yield, and (c) Bio-char yield.

ascribed to the secondary tar cracking and char decomposition, which can be confirmed by the reduce in liquid and char yields [2]. The secondary reactions of tar into gas prevail at temperatures above $600^{\circ} \mathrm{C}[1]$. The changing trend of product distribution with pyrolysis temperature was almost the same for cotton stalk pyrolysis with and without molten salt. For CS1MS10 pyrolysis, the gas yield distinctly increased from $31.07 \mathrm{wt} \%$ to $82.57 \mathrm{wt} \%$ with pyrolysis temperature rising from 450 to $850^{\circ} \mathrm{C}$ (Fig. 2a), while the liquid yield decreased from 35.67 wt\% to 28.68 wt\% (Fig. 2b), char yield remarkably decreased from $38.50 \mathrm{wt} \%$ to $19.50 \mathrm{wt} \%$ (Fig. 2c).

For the same pyrolysis temperature, the use of molten salt as pyrolysis media increased gas yield at the expense of liquid product or char. The increase of gas yield was strongly due to the catalytic activity of the alkali species in the molten salt for cotton stalk pyrolysis. Molten salt made sure a fast heat transfer rate because of its high thermal conductivity and heat capacity [11]. Then the cotton stalk thorough dispersion in liquid salt enabled rapid heating for higher pyrolysis rate [22]. It was expected to obtain more primary vapor products due to more rapid devolatilization at pyrolysis [33]. With the help of alkali carbonate salts catalysis effect, the primary vapor secondary cracking reaction into gas product would be promoted at higher pyrolysis temperature [34]. Meanwhile, the char and molten slat might react to produce more gas at higher temperature $\left(>700^{\circ} \mathrm{C}\right)$ [35], and this also made the mass balance of pyrolysis over $100 \%$ at high temperature $\left(750\right.$ and $\left.850^{\circ} \mathrm{C}\right)$. Then the increase of gas yield became more significant with increasing pyrolysis temperature indicated in Fig. 2 a.

At pyrolysis temperature of $850^{\circ} \mathrm{C}$, the gas yield continued to rise from $64.31 \mathrm{wt} \%$ to $82.57 \mathrm{wt} \%$ when mass ratio of molten salt to cotton stalk increased from 0.5 to 10 shown in Fig. 2a. A higher molten salt mass ratio meant more effective contact of alkali carbonates with the cotton stalk so that the secondary reaction of tar into gas product increased [23]. Meanwhile, more molten salt could participate in the reaction with char, thus producing more gas. However, there was no statistically significant change in gas yield with different molten salt mass ratios when the pyrolysis temperatures were lower than $850^{\circ} \mathrm{C}$. It was mainly attributed to the not so obvious catalytic effect of molten salt $\left(\mathrm{Na}_{2} \mathrm{CO}_{3}\right.$ and $\left.\mathrm{K}_{2} \mathrm{CO}_{3}\right)$ for tar secondary reactions and the reaction with char when the temperature was lower than $800^{\circ} \mathrm{C}$ [22].

The existence of molten salt could not only catalyze the decomposition of volatile matter, but also might inhibit the release of volatile matter, thus reducing the yield of the bio-oil and increased the yield of bio-char. Yasunishi, A. et al. [14] has also found that when wood was pyrolyzed in molten carbonates, the yield of liquid products decreased while the yields of gas and char increased. The inhibitory effect of molten salt on volatile release enhanced with the increase of molten salt mass ratio. So the liquid yields obtained from CS1MS5 and CS1MS10 were lower than those from CS1MS0.5 and CS1MS1 indicated in Fig. 2b.

It was observed that molten salt use slightly increased the char yield at low pyrolysis temperatures $\left(450-650^{\circ} \mathrm{C}\right.$ ) but it further decreased when temperature increased to $850^{\circ} \mathrm{C}$ (Fig. 2c). The displacement of pyrolysis reaction at lower temperatures induced by alkali metals favors the charring reactors versus fragmentation and depolymerization reactions in the primary decomposition of biomass, thereby increasing char yield [36]. The decrease of char yield at higher temperatures $\left(750\right.$ and $\left.850^{\circ} \mathrm{C}\right)$ were mainly because $\mathrm{K}_{2} \mathrm{CO}_{3}$ and $\mathrm{Na}_{2} \mathrm{CO}_{3}$ could further promote the cleavage of $\mathrm{C}-\mathrm{H}$ and $\mathrm{C}-\mathrm{O}$ bonds and aromatization of char during pyrolysis [37] while carbon in the char would simultaneously reacted with carbonates as the reaction (1) [38]. However, considering the error bars, there was no big difference of the char yields obtained with different molten salt mass ratios under the same pyrolysis temperature.

$\mathrm{CO}_{3}^{2-}+\mathrm{C} \rightarrow 2 \mathrm{CO}+\mathrm{O}^{2-}$ 


\subsection{Pyrolysis gas composition}

Fig. 3 shows the yields of $\mathrm{H}_{2}, \mathrm{CO}_{2}, \mathrm{CO}, \mathrm{CH}_{4}$ and $\mathrm{C}_{2+}$ during pyrolysis of cotton stalk without and with molten salt at different temperatures. For CS pyrolysis (without molten salt), the $\mathrm{H}_{2}$ releasing clearly increased from 2.15 to $81.64 \mathrm{ml} / \mathrm{g}$ with pyrolysis temperature increasing from 450 to $850^{\circ} \mathrm{C}$ shown in Fig. 3a. And CO distinctly increased from 42.07 to $138.55 \mathrm{ml} / \mathrm{g}$ depicted in Fig. 3b, $\mathrm{CH}_{4}$ noticeably increased from 8.93 to $47.86 \mathrm{ml} / \mathrm{g}$ indicated in Fig. 3c, $C_{2+}$ increased from 5.00 to $18.68 \mathrm{ml} / \mathrm{g}$ as shown in Fig. 3d. While, temperature had a limited influence on the yield of $\mathrm{CO}_{2}$ in this temperature range (Fig. 3e). Below $450-550^{\circ} \mathrm{C}$, most of permanent gases directly came from degradation of biomass chemical structures (hemicellulose, cellulose and lignin) as volatiles secondary reactions was negligible [1]. However, the increase of $\mathrm{H}_{2}$ and $\mathrm{CO}$ were mainly due to tar secondary reactions as temperature increases above $450-550^{\circ} \mathrm{C}$ [39]. Simultaneously, most of the remaining tars convert into $\mathrm{CH}_{4}$ and $\mathrm{C}_{2+}$ [4].

The changing trend of gas compositions with pyrolysis temperature was almost the same for cotton stalk pyrolysis with and without molten salt. For CS1MS10 pyrolysis, $\mathrm{H}_{2}$ yield clearly increased from 11.33 to $162.43 \mathrm{ml} / \mathrm{g}$ with pyrolysis temperature increasing from 450 to $850^{\circ} \mathrm{C}$ shown in Fig. 3a. And CO distinctly increased from 36.60 to $388.68 \mathrm{ml} / \mathrm{g}$ depicted in Fig. $3 \mathrm{~b}, \mathrm{CH}_{4}$
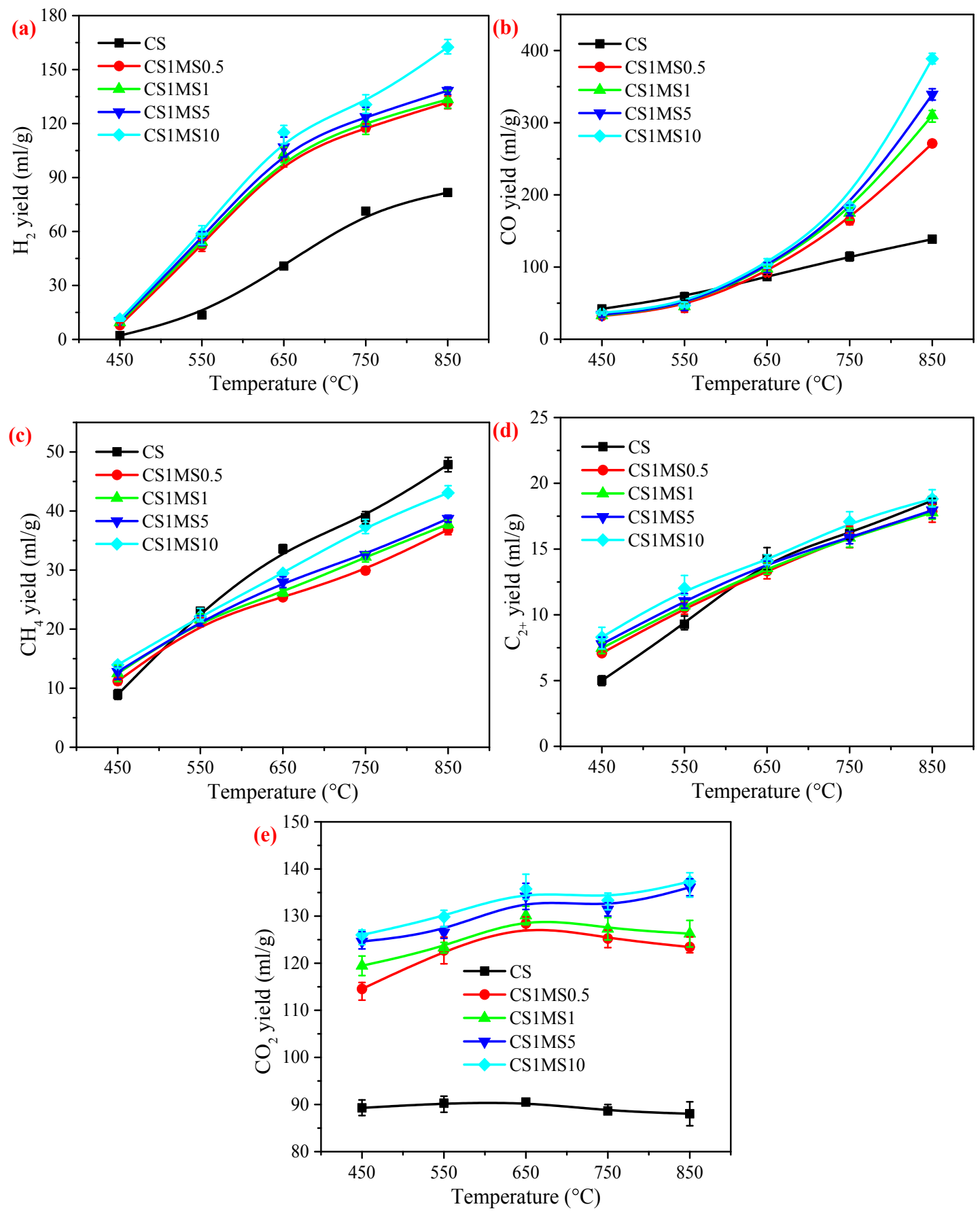

Fig. 3. Effects of temperature and molten salt amount on the gas product compositions of solar pyrolysis: (a) $\mathrm{H}_{2}$ yield, (b) $\mathrm{CO}_{\text {yield, }}(\mathrm{c}) \mathrm{CH}_{4}$ yield, (d) $\mathrm{C}_{2+}$ yield, and (e) $\mathrm{CO}_{2}$ yield 
noticeably increased from 13.96 to $43.07 \mathrm{ml} / \mathrm{g}$ indicated in Fig. 3c, $\mathrm{C}_{2+}$ increased from 8.30 to $18.81 \mathrm{ml} / \mathrm{g}$ as observed in Fig. 3d. At the same pyrolysis temperature, $\mathrm{H}_{2}$ yield showed a general increasing trend with molten salt media (Fig. 3a). With Na containing molten salt, the added $\mathrm{Na}^{+}$and $-\mathrm{COOH}$ or $-\mathrm{OH}$ groups in cotton stalk reacted as reactions (2) and (3) for releasing $\mathrm{H}^{+}$, which promoted $\mathrm{H}_{2}$ formation [40]. Furthermore, the increase trend of $\mathrm{H}_{2}$ yield became more pronounced with pyrolysis temperature rising. It was mainly due to the enhancing catalytic activity of the alkali species in the molten salt for tar cracking reaction (4) at higher temperatures [11].

$\mathrm{Na}^{+}+-\mathrm{COOH} \rightarrow-\mathrm{COONa}+\mathrm{H}^{+}$

$\mathrm{Na}^{+}+-\mathrm{OH} \rightarrow-\mathrm{ONa}+\mathrm{H}^{+}$

$\left[\mathrm{C}_{\mathrm{x}} \mathrm{H}_{\mathrm{y}} \mathrm{O}_{\mathrm{z}}\right] \rightarrow \mathrm{C}+\mathrm{Tar}+\mathrm{CO}+\mathrm{H}_{2}+\mathrm{CH}_{4}+\mathrm{C}_{\mathrm{n}} \mathrm{H}_{\mathrm{m}}$

Using molten salt as pyrolysis media also increased $\mathrm{CO}$ yield by 1-3 times compared to those without molten salt when temperature was above $550{ }^{\circ} \mathrm{C}$. The catalytic cracking of tar at higher temperatures for producing $\mathrm{CO}$ as (4) was enhanced by molten salt [40]. With the use of molten salt $\left(\mathrm{Na}_{2} \mathrm{CO}_{3}\right.$ and $\left.\mathrm{K}_{2} \mathrm{CO}_{3}\right), \mathrm{CO}_{2}$ produced during primary pyrolysis stage would react with carbon bonded with $\mathrm{Na}$ or $\mathrm{K}$ as reactions (5), (6) and (7) before its evolution from biomass or coke surface [23]. What's more, the char would react with carbonates over $700{ }^{\circ} \mathrm{C}$ for generating $\mathrm{CO}$ by an intermolecular redox reaction (1) [38]. The extend of these reactions increased with temperature rising, and therefore $\mathrm{CO}$ yield increase became more and more significant with increasing temperature.

$\mathrm{M}_{2} \mathrm{CO}_{3}+2 \mathrm{C} \rightarrow 2 \mathrm{M}+3 \mathrm{CO}$

$2 \mathrm{M}+\mathrm{CO}_{2} \rightarrow \mathrm{M}_{2} \mathrm{O}+\mathrm{CO}$

$\mathrm{M}_{2} \mathrm{O}+\mathrm{CO}_{2} \rightarrow \mathrm{M}_{2} \mathrm{CO}_{3}$

In contrast, a lower $\mathrm{CH}_{4}$ production was in the molten salt pyrolysis when temperature was above $550{ }^{\circ} \mathrm{C}$ (Fig. 3c). It was consistent with a report that $30 \%$ of $\mathrm{CH}_{4}$ conversion at $900{ }^{\circ} \mathrm{C}$ in molten salt as (8) [41]. A comparison between pyrolysis without and with molten salt showed that variation on the yields of $\mathrm{C}_{2+}$ were very small (Fig. 3d). It was also reported by Blasi et al. [36]. Significant increase was observed for $\mathrm{CO}_{2}$ with the use of molten salt (Fig. 3e). The increase of $\mathrm{CO}_{2}$ was mainly due to $\mathrm{CO}$ conversion via water gas shift reaction (9) and partly because of carbonate salt decomposition reactions (10), (11) [12,23].

$\mathrm{CH}_{4} \rightarrow \mathrm{C}+2 \mathrm{H}_{2}$

$\mathrm{CO}+\mathrm{H}_{2} \mathrm{O} \rightarrow \mathrm{CO}_{2}+\mathrm{H}_{2}$

$\mathrm{M}_{2} \mathrm{CO}_{3}+\mathrm{H}_{2} \mathrm{O} \rightarrow 2 \mathrm{MOH}+\mathrm{CO}_{2}$

$\mathrm{M}_{2} \mathrm{CO}_{3} \rightarrow \mathrm{M}_{2} \mathrm{O}+\mathrm{CO}_{2}$

It indicated that the increase of mass ratio of molten salt to cotton stalk from 0.5 to 10 could promote $\mathrm{H}_{2}$ and $\mathrm{CO}$ production at pyrolysis temperature of $850^{\circ} \mathrm{C}$. Increasing molten salt content increased the secondary reaction of tar since more tar could contact with the salt. However, there was almost no change in $\mathrm{H}_{2}$ and $\mathrm{CO}$ yields with different molten salt mass ratios when the pyrolysis temperatures were lower than $850^{\circ} \mathrm{C}$. As shown in Fig. $3 \mathrm{c}$ and e, the yields of $\mathrm{CH}_{4}$ and $\mathrm{CO}_{2}$ obtained with 10 and 5 mass ratio of molten salt to cotton stalk was higher than those with 0.5 and 1 mass ratio of molten salt to cotton stalk. This may be because more alkali metal salts $(\mathrm{Na}, \mathrm{K})$ could promote the cracking and catalytic reforming reactions between organic compounds and methane [42].

\subsection{Bio-oil characterization}

Fig. 4 describes the composition of bio-oil from cotton stalk pyrolysis without and with molten salt at temperatures of $450-850^{\circ} \mathrm{C}$. Bio-oil contained a wide range of organic compounds that can be divided into several main groups: Acids, Linear alcohols/ aldehydes/ketones, Furans, Cyclopentanones, Phenols, Aromatics and N-species. For cotton stalk pyrolysis (Fig. 4a), the relative content of aromatics tended to increase from $10.07 \%$ to $45.30 \%$ with the pyrolysis temperature from 450 to $850^{\circ} \mathrm{C}$. Significantly higher aromatic hydrocarbons could be attributed to the enhanced formation of polycyclic aromatic hydrocarbons (PAHs) such as phenanthrene, anthracene, naphthalene with temperature rising [43]. While acids, linear alcohols/aldehydes/ketones and phenols gradually reduced from temperature $450-850^{\circ} \mathrm{C}$. This was because these functional groups were mainly formed from the
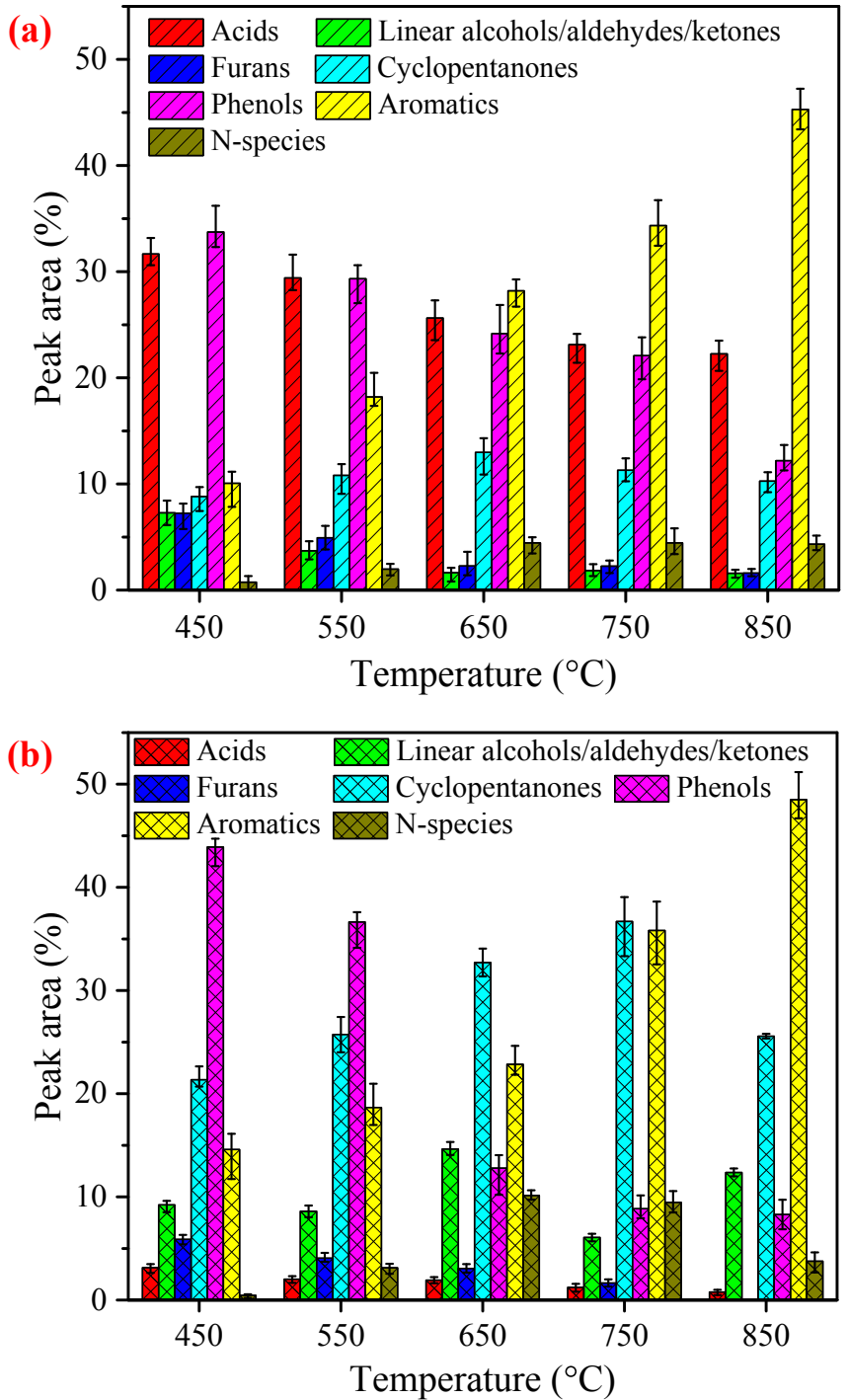

Fig. 4. Effects of temperature on the bio-oil chemical composition from solar pyrolysis of: (a) CS and (b) CS1MS1. 
depolymerization of hemicellulose and cellulose at temperature lower than $350^{\circ} \mathrm{C}$ [44]. As the final pyrolysis temperature increased, the functional groups experienced secondary cracking for producing more stable species.

For cotton stalk pyrolysis with molten salt (Fig. 4b), the changing trend of bio-oil composition with pyrolysis temperature was very different from that without molten salt. Molten salt pyrolysis caused a noticeable decrease in bio-oil acids content $3.14 \%-0.77 \%$ versus $31.67 \%-22.26 \%$ of original cotton stalk) among pyrolysis temperature range of $450-850^{\circ} \mathrm{C}$. The decrease of acids was mainly due to enhanced catalytic cracking of the cracking of carboxylic acids by molten salt components $\left(\mathrm{Li}_{2} \mathrm{CO}_{3}-\mathrm{Na}_{2} \mathrm{CO}_{3}-\mathrm{K}_{2} \mathrm{CO}_{3}\right)$ [45]. Moreover, alkali and alkaline earth metals in molten salt were able to promote the catalytic conversion of acidic substances and oxygenates in the bio-oil through ketonization and the aldol reaction for more ketones production [46]. However, the cyclopentanones content in molten salt pyrolysis was more than twice that of pyrolysis without molten salt. The addition of $\mathrm{Li}, \mathrm{Na}$ or $\mathrm{K}$ in molten salt would be attributed to the improvement of cyclopentanones formation, as they would enhance the cleavage of $\mathrm{C}-\mathrm{O}$ bond and the formation of new C-C bond in bio-oil [47]. When cotton stalk was pyrolyzed in molten salt, phenols significantly decreased. In the presence of alkali and alkaline earth metal catalyst, lignin-derived phenolics undergo oxygen-aromatic carbon bond cleavage to form aromatic hydrocarbons $[48,49]$. It was also confirmed by the fact that molten salt presence increased the relative content of aromatics in the bio-oil.

The main functional groups (Acids, O-species (furans/aldehydes/ ketones/alcohols), Phenols and Aromatics) are selected for further comparison indicated in Fig. 5. As depicted in Fig. 5a, the reduction of acids in pyrolysis bio-oil was most evident when the mass ratio of molten salt to cotton stalk was 10 . The most obvious decrease of acid was mainly due to optimum catalytic effect achieved with this mass ratio [19]. However, with the mass ratio of molten salt to cotton stalk increased from 0.5 to 10 , the relative content of acids in pyrolysis bio-oil gradually decreased. As shown in Fig. 5b, the ospecies (furans/aldehydes/ketones/alcohols) increased when mass ratio of molten salt to cotton stalk increased from 0.5 to 10 at lower pyrolysis temperature $\left(450,550\right.$ and $\left.650^{\circ} \mathrm{C}\right)$. Ketonization and the aldol reactions for more ketones and alcohols production were promoted due to the effective contact of bio-oil compounds with more molten salt catalyst at high mass ratio of molten salt to cotton stalk. However, the o-species might be transformed into gaseous products, which would reduce its relative content at high temperature. Increasing molten salt mass ratio promoted the catalytic cracking of phenols when pyrolysis temperature above $550{ }^{\circ} \mathrm{C}$ indicated in Fig. 5c. It should be noted from Fig. 5d that there was positive correlation between the increased content of aromatics and mass ratio of molten salt to cotton stalk (from 0.5 to 10). In fact, the higher the molten salt ratio was used, the better dispersion of cotton stalk in molten salt obtained. Then increasing molten salt content increased the secondary tar reaction of into aromatics since it enhanced the catalytic effect of molten salt $\left(\mathrm{Na}_{2} \mathrm{CO}_{3}\right.$ and $\left.\mathrm{K}_{2} \mathrm{CO}_{3}\right)$ [23].

\subsection{Bio-char characterization}

The elemental analysis of bio-char obtained from pyrolysis of cotton stalk without and with molten salt are listed in Table 1. For cotton stalk pyrolysis, the carbon content in bio-char increased with increasing pyrolysis temperature while the hydrogen and oxygen contents declined sharply. The carbonaceous structure graphitization at high temperatures lead to increased the carbon content [33]. The decrease of hydrogen and oxygen contents was due to the char weak bonds cracking and cleavage [50]. The changing trend of bio-char composition with pyrolysis temperature
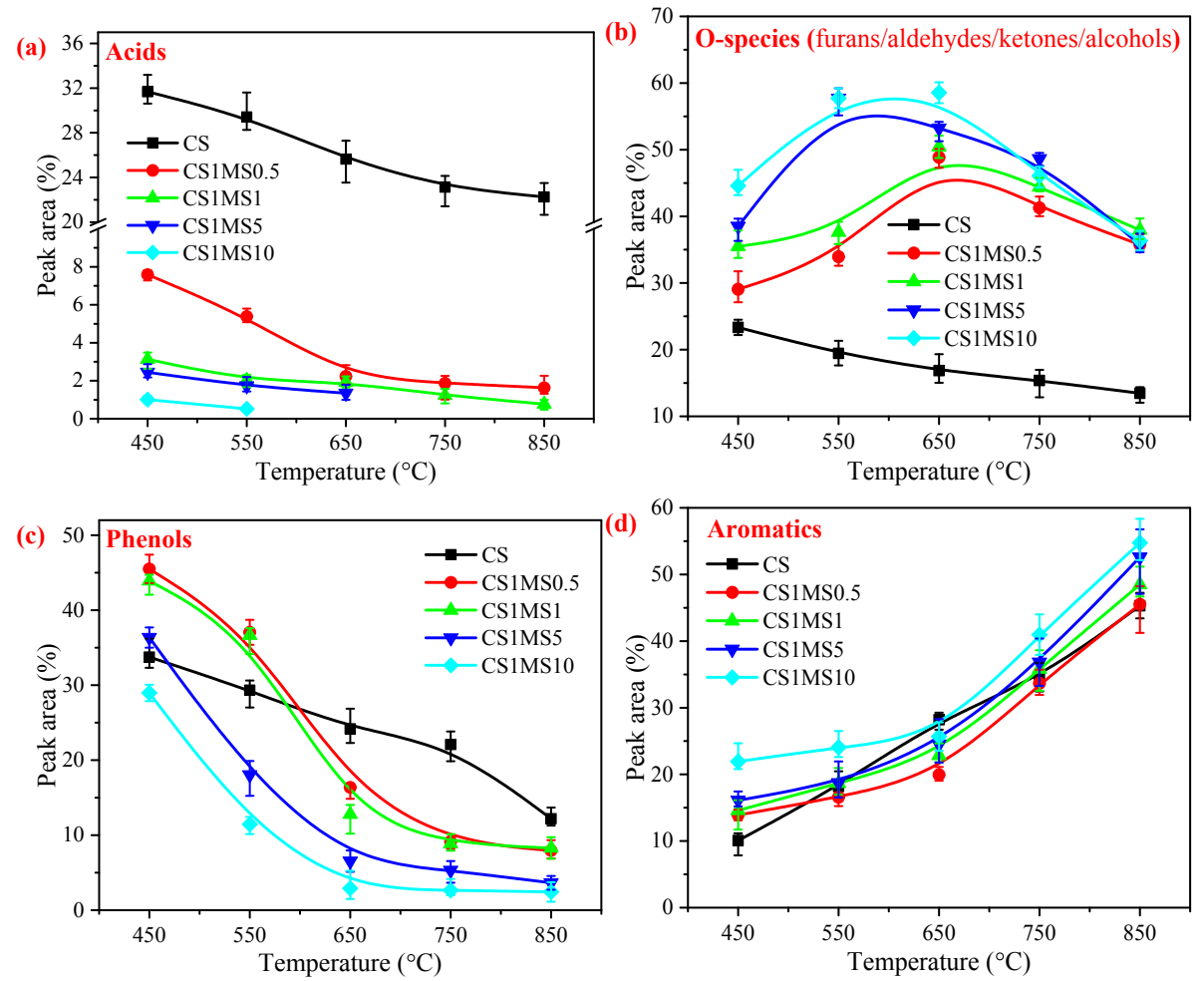

Fig. 5. Effects of temperature and molten salt amount on the main functional group distribution of bio-oil from solar pyrolysis: (a) Acetic acid, (b) O-species (furans/aldehydes/ ketones/alcohols), (c) Phenols, and (d) Aromatics. 
Table 1

Effect of pyrolysis temperature and mass ratio of molten salt to biomass on char composition.

\begin{tabular}{lllll}
\hline Char samples & \multicolumn{4}{l}{ Ultimate analysis (wt.\%, daf) } \\
\cline { 2 - 5 } & $\mathrm{C}$ & $\mathrm{H}$ & $\mathrm{N}$ & $\mathrm{O}^{\mathrm{a}}$ \\
\hline CS-450 & 81.97 & 3.51 & 1.89 & 12.63 \\
CS-550 & 86.06 & 3.10 & 1.76 & 9.08 \\
CS-650 & 90.13 & 2.45 & 1.44 & 5.98 \\
CS-750 & 93.42 & 1.96 & 1.31 & 3.31 \\
CS-850 & 94.42 & 1.56 & 1.34 & 2.69 \\
CS1MS0.5-550 & 83.70 & 2.66 & 1.27 & 12.37 \\
CS1MS0.5-850 & 84.92 & 1.02 & 0.62 & 13.44 \\
CS1MS1-550 & 75.79 & 2.59 & 1.19 & 20.43 \\
CS1MS1-850 & 81.85 & 1.75 & 0.28 & 16.12 \\
CS1MS5-550 & 77.86 & 3.60 & 1.27 & 17.27 \\
CS1MS5-850 & 83.71 & 1.25 & 0.16 & 14.88 \\
CS1MS10-450 & 74.16 & 3.51 & 1.29 & 21.04 \\
CS1MS10-550 & 78.54 & 2.61 & 1.23 & 17.63 \\
CS1MS10-650 & 78.44 & 2.31 & 1.01 & 18.24 \\
CS1MS10-750 & 79.16 & 2.11 & 0.45 & 18.28 \\
CS1MS10-850 & 78.98 & 1.53 & 0.09 & 19.40 \\
\hline
\end{tabular}

daf: dry ash free basis.

${ }^{a}$ By difference.

was different for cotton stalk pyrolysis with and without molten salt. At the same pyrolysis temperature, carbon content showed a general decreasing trend while oxygen increased with molten salt media. The decrease of carbon content was mainly due to the enhanced C-C bonds cleavage by alkaline metals in molten salt [36]. Alkaline cations due to small size could penetrate into the biomass/ char structure and cause the bond of oxygen as reactions (2) and (3) [40]. However, there was no obvious influence of molten salt mass ratio on bio-char composition.

Table 2 lists the BET surface area and pore volume of bio-char obtained from pyrolysis of cotton stalk without and with molten salt. For cotton stalk pyrolysis, the BET surface area increased from 2.12 to $222.31 \mathrm{~m}^{2} / \mathrm{g}$ as temperature increased from 450 to $850{ }^{\circ} \mathrm{C}$. Meanwhile, the micropore volume increased from 0.0011 to $0.0978 \mathrm{~cm}^{3} / \mathrm{g}$, the total pore volume increased from 0.0038 to $0.1395 \mathrm{~cm}^{3} / \mathrm{g}$. Intensifying volatile release with increasing temperature caused the increase of surface area and pore volume [50]. The changing trend of bio-char BET surface area and pore volume with pyrolysis temperature was almost the same for cotton stalk pyrolysis with and without molten salt. At the same pyrolysis temperature, BET surface and pore volume showed an obvious increasing trend with molten salt media. For CS1MS10 pyrolysis, the BET surface area increased from $1.90 \mathrm{~m}^{2} / \mathrm{g}$ to $873.44 \mathrm{~m}^{2} / \mathrm{g}$ as temperature increased from 450 to $850^{\circ} \mathrm{C}$. And the micropore volume increased from 0.0009 to $0.3210 \mathrm{~cm}^{3} / \mathrm{g}$, the total pore volume increased from 0.0051 to $0.5567 \mathrm{~cm}^{3} / \mathrm{g}$.

At $850^{\circ} \mathrm{C}$, the BET surface area of CS1MS10 bio-char increased about 4 times compared with that of CS bio-char. Simultaneously, both of micropore and total pore volumes increased about 4 times. The use of molten salt catalyzed the pyrolysis reaction of cotton stalk, which enhanced volatile release for creating bio-char with higher BET surface area and pore volume. In addition, the generated $\mathrm{H}_{2} \mathrm{O}$ and $\mathrm{CO}_{2}$ during pyrolysis process reacted with carbon for porous carbon formation, which called activation process [51]. Molten salt just could promote the activation process for more porous bio-char with high surface area and pore volume. However, bio-char obtained from C1MS5 pyrolysis at $850^{\circ} \mathrm{C}$ had the highest surface area of $972.57 \mathrm{~m}^{2} / \mathrm{g}$ and the biggest total pore volume of $0.6203 \mathrm{~cm}^{3} / \mathrm{g}$. BET surface area and pore volume of bio-char decreased with mass ratio of molten salt to cotton stalk increasing from 5 to 10 . The results proved that loading excessive amounts of molten salt could enter the inner interspace through the surface crack of char, which resulted in blocking some micropores and decreasing the specific surface of bio-char [40].

\section{Conclusion}

Solar pyrolysis of cotton stalk in molten salt media has been investigated with a $4 \mathrm{~kW}$ solar simulator. At pyrolysis temperature of $850^{\circ} \mathrm{C}$, the syngas mainly composed of $\mathrm{CO}$ and $\mathrm{H}_{2}$, continued to rise from $41.35 \mathrm{wt} \%$ to $82.57 \mathrm{wt} \%$ when mass ratio of molten salt to cotton stalk increased from 0 to 10 . Pyrolysis in molten salt significantly decreased bio-oil acids $(3.14 \%-0.77 \%$ versus $31.67 \%-$ $22.26 \%$ of original cotton stalk) and phenols, while increased aromatics among pyrolysis temperature range of $450-850^{\circ} \mathrm{C}$. There was positive correlation between the increased content of aromatics and mass ratio of molten salt to cotton stalk (from 0.5 to 10). The bio-char carbon content showed a general decreasing trend while oxygen, BET surface and pore volume increased with using molten salt as pyrolysis media. BET surface area and pore volume of bio-char decreased with mass ratio of molten salt to cotton stalk increasing from 5 to 10 . Solar pyrolysis of biomass in molten salt can be considered as a promising method for producing syngas (rich in $\mathrm{H}_{2}$ and $\mathrm{CO}$ ), high quality bio-oil (little acids) and bio-char (large BET surface area), which storing solar energy in chemical form at the same time.

Table 2

Effect of pyrolysis temperature and mass ratio of molten salt to biomass on char surface area and pore volume.

\begin{tabular}{lll}
\hline Char samples & BET surface area $\left(\mathrm{m}^{2} / \mathrm{g}\right)$ & Pore volume of micropore $\left(\mathrm{cm}^{3} / \mathrm{g}\right)$ \\
\hline CS-450 & 2.12 & 0.0011 \\
CS-550 & 11.63 & 0.0155 \\
CS-650 & 84.24 & 0.0320 \\
CS-750 & 192.26 & 0.0854 \\
CS-850 & 222.31 & 0.0978 \\
CS1MS0.5-550 & 5.68 & 0.0040 \\
CS1MS0.5-850 & 802.29 & 0.2935 \\
CS1MS1-550 & 1.41 & 0.0018 \\
CS1MS1-850 & 904.60 & 0.3128 \\
CS1MS5-550 & 1.94 & 0.0027 \\
CS1MS5-850 & 972.57 & 0.2881 \\
CS1MS10-450 & 1.90 & 0.0009 \\
CS1MS10-550 & 6.08 & 0.0035 \\
CS1MS10-650 & 340.41 & 0.1533 \\
CS1MS10-750 & 641.49 & 0.2784 \\
CS1MS10-850 & 873.44 & 0.3210 \\
\hline
\end{tabular}




\section{Acknowledgement}

This work was supported by the National Natural Science Foundation of China (Project No. 51706083 and 51622604), and Natural Science Foundation of Shenzhen (JCYJ20170818164006890). We also express appreciation of the technical support from Analytical and Testing Center in Huazhong University of Science \& Technology (http://atc.hust.edu.cn).

\section{References}

[1] Neves D, Thunman H, Matos A, Tarelho L, Gomez-Barea A. Characterization and prediction of biomass pyrolysis products. Prog Energy Combust Sci 2011;37:611-30.

[2] Zeng K, Gauthier D, Li R, Flamant G. Solar pyrolysis of beech wood: effects of pyrolysis parameters on the product distribution and gas product composition. Energy 2015;93:1648-57.

[3] Zeng K, Gauthier D, Lu J, Flamant G. Parametric study and process optimization for solar pyrolysis of beech wood. Energy Convers Manag 2015;106: 987-98.

[4] Zeng K, Gauthier D, Doan Pham M, Weiss-Hortala E, Nzihou A, Flamant G. Characterization of solar fuels obtained from beech wood solar pyrolysis. Fuel 2017;188:285-93.

[5] Zeng K, Gauthier D, Soria J, Mazza G, Flamant G. Solar pyrolysis of carbonaceous feedstocks: a review. Sol Energy 2017;156:73-92.

[6] Lede J. Solar thermochemical conversion of biomass. Sol Energy 1999;65: $3-13$.

[7] Hopkins MW, Dejenga C, Antal MJ. The flash pyrolysis of cellulosic materials using concentrated visible light. Sol Energy 1984;32:547-51.

[8] Zeng K, Soria J, Gauthier D, Mazza G, Flamant G. Modeling of beech wood pellet pyrolysis under concentrated solar radiation. Renew Energy 2016;99: 721-9.

[9] Zeng K, Gauthier D, Li R, Flamant G. Combined effects of initial water content and heating parameters on solar pyrolysis of beech wood. Energy 2017;125 $552-61$.

[10] Nygård HS, Olsen E. Review of thermal processing of biomass and waste in molten salts for production of renewable fuels and chemicals. Int J Low Carbon Technol 2012;7:318-24.

[11] Hathaway BJ, Davidson JH, Kittelson DB. Solar gasification of biomass: kinetics of pyrolysis and steam gasification in molten salt. J Sol Energy Eng TransASME. 2011;133. 021011-1-9.

[12] Hathaway BJ, Honda M, Kittelson DB, Davidson JH. Steam gasification of plant biomass using molten carbonate salts. Energy 2013;49:211-7.

[13] Ratchahat S, Kodama S, Tanthapanichakoon W, Sekiguchi H. Combined molten salt-Ni/Al2O3 as synergistic medium for high-quality syngas production. Chem Eng J 2015;278:224-33.

[14] Yasunishi A, Tada Y. Wood pyrolysis in molten-salt. Kagaku Kogaku Ronbunshu 1985;11:346-9.

[15] Nygard HS, Danielsen F, Olsen E. Thermal history of wood particles in molten salt pyrolysis. Energy Fuels 2012;26:6419-25.

[16] Caubet S, Corte P, Fahim C, Traverse JP. Thermochemical conversion of biomass: gasification by flash pyrolysis study. Sol Energy 1982;29:565-72.

[17] Tada Y, Yasunishi A. Wood pyrolysis with molten-salt as heating medium Kagaku Kogaku Ronbunshu 1987;13:376-9.

[18] Serrano D, Horvat A, Sobrino C, Sánchez-Delgado S. Thermochemical conversion of C. cardunculus L. in nitrate molten salts. Appl Therm Eng 2019;148: 136-46.

[19] Jiang H, Ai N, Wang M, Ji D, Ji J. Experimental study on thermal pyrolysis of biomass in molten salt media. Electrochemistry 2009;77:730-5.

[20] Sada E, Kumazawa H, Kudsy M. Pyrolysis of lignins in molten salt media. Ind Eng Chem Res 1992;31:612-6.

[21] Kudsy M, Kumazawa H. Pyrolysis of kraft lignin in the presence of molten ZnCl2-KCl mixture. Can J Chem Eng 1999;77:1176-84.

[22] Adinberg R, Epstein M, Karni J. Solar gasification of biomass: a molten salt pyrolysis study. J Sol Energy Eng Trans-ASME. 2004:126:850-7.

[23] Rizkiana J, Guan GQ, Widayatno WB, Hao XG, Wang ZD, Zhang ZL, et al. Oil production from mild pyrolysis of low-rank coal in molten salts media. App Energy 2015;154:944-50.

[24] Olivares RI, Chen C, Wright S. The thermal stability of molten lithium-sodium-potassium carbonate and the influence of additives on the melting point. J Sol Energy Eng 2012;134. 041002-1-8.

[25] Xiao J, Wei X, Gilaber RN, Zhang Y, Li Z. Design and characterization of a highflux non-coaxial concentrating solar simulator. Appl Therm Eng 2018;145:
$201-11$

26] Gallo A, Marzo A, Fuentealba E, Alonso E. High flux solar simulators for concentrated solar thermal research: a review. Renew Sustain Energy Rev 2017;77:1385-402.

[27] Arribas L, Arconada N, González-Fernández C, Löhrl C, González-Aguilar J, Kaltschmitt M, et al. Solar-driven pyrolysis and gasification of low-grade carbonaceous materials. Int J Hydrogen Energy 2017;42:13598-606.

[28] Müller F, Poživil P, van Eyk PJ, Villarrazo A, Haueter P. Wieckert C, et al A pressurized high-flux solar reactor for the efficient thermochemical gasification of carbonaceous feedstock. Fuel 2017;193:432-43.

[29] Petrasch Jr, Coray P, Meier A, Brack M, Häberling P, Wuillemin D, et al. A novel 50 kW 11,000 suns high-flux solar simulator based on an array of xenon arc lamps. J Sol Energy Eng 2007;129:405-11.

[30] Zeng K, Yang Q, Che Q, Zhang Y, Wang X, Yang H, et al. Effects of temperature and $\mathrm{Mg}$-based additives on properties of cotton stalk torrefaction products. Energy Fuels 2018;32:9640-9.

[31] Chen Y, Yang H, Wang X, Zhang S, Chen H. Biomass-based pyrolytic polygeneration system on cotton stalk pyrolysis: influence of temperature. Bioresour Technol 2012;107:411-8.

[32] Zeng K, Yang Q, Zhang Y, Mei Y, Wang X, Yang H, et al. Influence of torrefaction with Mg-based additives on the pyrolysis of cotton stalk. Bioresour Technol 2018;261:62-9.

[33] Zeng K, Doan Pham M, Gauthier D, Weiss-Hortala E, Nzihou A, Flamant G. The effect of temperature and heating rate on char properties obtained from solar pyrolysis of beech wood. Bioresour Technol 2015;182:114-9.

[34] Nzihou A, Stanmore B, Sharrock P. A review of catalysts for the gasification of biomass char, with some reference to coal. Energy 2013:58:305-17.

[35] Lee CG, Hur H. Gasification of bamboo carbon with molten alkali carbonates. Korean J Chem Eng 2011;28:1539-45.

[36] Blasi CD, Galgano A. Influences of the chemical state of alkaline compounds and the nature of AlkaliMetal on wood pyrolysis. Ind Eng Chem Res 2009;48: 3359-69.

[37] Hu S, Jiang L, Wang Y, Su S, Sun L, Xu B, et al. Effects of inherent alkali and alkaline earth metallic species on biomass pyrolysis at different temperatures. Bioresour Technol 2015; 192:23-30.

[38] Nagase K, Shimodaira T, Itoh M, Zheng YT. Kinetics and mechanisms of the reverse Boudouard reaction over metal carbonates in connection with the reactions of solid carbon with the metal carbonates. Phys Chem Chem Phys 1999;1:5659-64.

[39] Morf P, Hasler P, Nussbaumer T. Mechanisms and kinetics of homogeneous secondary reactions of tar from continuous pyrolysis of wood chips. Fuel 2002;81:843-53.

[40] Ding L, Zhou Z, Guo Q, Huo W, Yu G. Catalytic effects of Na2CO3 additive on coal pyrolysis and gasification. Fuel 2015;142:134-44.

[41] Xianquan AO, Hua W, Yonggang WEI, Kongzhai LI, Mingchun LIU, Reduction behavior of methane in alkali molten carbonates. I Fuel Chem Technol 2008;36:455-61.

[42] Zhou L, Jia Y, Tuan-Huy N, Adesina AA, Liu Z. Hydropyrolsis characteristics and kinetics of potassium-impregnated pine wood. Fuel Process Technol 2013;116:149-57.

[43] Akhtar J, Amin NS. A review on operating parameters for optimum liquid oil yield in biomass pyrolysis. Renew Sustain Energy Rev 2012;16:5101-9.

[44] Collard F-X, Blin J. A review on pyrolysis of biomass constituents: mechanisms and composition of the products obtained from the conversion of cellulose, hemicelluloses and lignin. Renew Sustain Energy Rev 2014;38:594-608.

[45] Wang S, Guo Z, Cai Q, Guo L. Catalytic conversion of carboxylic acids in bio-oil for liquid hydrocarbons production. Biomass Bioenergy 2012;45:138-43.

[46] Stefanidis SD, Kalogiannis KG, Iliopoulou EF, Lappas AA, Pilavachi PA. In-situ upgrading of biomass pyrolysis vapors: catalyst screening on a fixed bed reactor. Bioresour Technol 2011:102:8261-7.

[47] Zhou M, Li J, Wang K, Xia H, Xu J, Jiang J. Selective conversion of furfural to cyclopentanone over CNT-supported $\mathrm{Cu}$ based catalysts: model reaction for upgrading of bio-oil. Fuel 2017;202:1-11.

[48] Mourant D, Wang Z, He M, Wang XS, Garcia-Perez M, Ling K, et al, Mallee wood fast pyrolysis: effects of alkali and alkaline earth metallic species on the yield and composition of bio-oil. Fuel 2011;90:2915-22.

[49] Zabeti M, Nguyen TS, Lefferts L, Heeres HJ, Seshan K. In situ catalytic pyrolysis of lignocellulose using alkali-modified amorphous silica alumina. Bioresour Technol 2012;118:374-81.

[50] Kim KH, Kim J-Y, Cho T-S, Choi JW. Influence of pyrolysis temperature on physicochemical properties of biochar obtained from the fast pyrolysis of pitch pine (Pinus rigida). Bioresour Technol 2012;118:158-62.

[51] Yin H, Lu B, Xu Y, Tang D, Mao X, Xiao W, et al. Harvesting capacitive carbon by carbonization of waste biomass in molten salts. Environ Sci Technol 2014;48:8101-8. 